\title{
Effect of $n-3$ PUFA on extracellular matrix protein turnover in patients with psoriatic arthritis: a randomized, double-blind, placebo-controlled trial
}

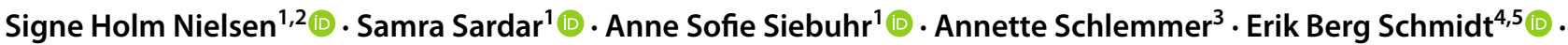

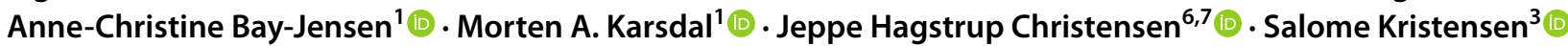

Received: 3 December 2020 / Accepted: 7 April 2021 / Published online: 22 April 2021

(c) The Author(s) 2021

\begin{abstract}
Psoriatic arthritis (PsA) is a chronic inflammatory disease characterized by involvement of skin, axial and peripheral skeleton. An altered balance between extracellular matrix (ECM) formation and breakdown is a key event in PsA, and changes in ECM protein metabolites may provide insight to tissue changes. Dietary fish oils (n-3 PUFA) might affect the inflammation driven tissue turnover. The aim was to evaluate ECM metabolites in patients with PsA compared to healthy individuals and investigate the effects of n-3 PUFA. The 24-week randomized, double-blind, placebo-controlled trial of PUFA included 142 patients with PsA. Fifty-seven healthy individuals were included for comparison. This study is a sub-study investigating biomarkers of tissue remodelling as secondary outcomes. Serum samples at baseline and 24 weeks and healthy individuals were obtained, while a panel of ECM metabolites reflecting bone and soft tissue turnover were measured by ELISAs: PROC1, PRO-C3, PRO-C4, C1M, C3M, C4M, CTX-I and Osteocalcin (OC). C1M, PRO-C3, PRO-C4 and C4M was found to be elevated in PsA patients compared to the healthy individuals (from 56 to $792 \%$, all $p<0.0001$ ), where no differences were found for OC, CTX-I, PRO-C1 and C3M. PRO-C3 was increased by 7\% in patients receiving n-3 PUFA after 24 weeks compared to baseline levels $(p=0.002)$. None of the other biomarkers was changed with $n-3$ PUFA treatment. This indicates that tissue turnover is increased in PsA patients compared to healthy individuals, while n-3 PUFA treatment for 24 weeks did not have an effect on tissue turnover. Trial registration NCT01818804. Registered 27 March 2013-Completed 18 February 2016. https://clinicaltrials.gov/ct2/show/NCT01818804?term=NCT01818804\&rank=1
\end{abstract}

Keywords Psoriatic arthritis $\cdot$ Collagens $\cdot$ Biomarkers $\cdot$ Fish oil

Signe Holm Nielsen

shn@nordicbio.com

Samra Sardar

samrasardar@gmail.com

Anne Sofie Siebuhr

aso@nordicbio.com

Annette Schlemmer

ANESHL@rm.dk

Erik Berg Schmidt ebs@rn.dk

Anne-Christine Bay-Jensen

acbj@nordicbio.com

Morten A. Karsdal

mk@nordicbio.com

Jeppe Hagstrup Christensen

jeppe.hagstrup.christensen@rn.dk

Salome Kristensen

sakr@rn.dk
Immunoscience, Nordic Bioscience, Herlev Hovedgade 207, 2730 Herlev, Denmark

2 Department of Biotechnology and Biomedicine, Technical University of Denmark, Lyngby, Denmark

3 Department of Rheumatology, Aalborg University Hospital, Aalborg, Denmark

4 Department of Cardiology, Aalborg University Hospital, Aalborg, Denmark

5 Department of Clinical Medicine, Aalborg University, Aalborg, Denmark

6 Department of Nephrology, Aalborg University Hospital, Aalborg, Denmark

7 Department of Clinical Medicine, Aalborg University, Aalborg, Denmark 


$\begin{array}{ll}\text { Abbreviations } \\ \text { PsA } & \text { Psoreatic arthritis } \\ \text { ECM } & \text { Extracellular matrix } \\ \text { PUFA } & \text { Polyunsaturated fatty acids } \\ \text { PRO-C1 } & \text { Collagen type I formation } \\ \text { PRO-C3 } & \text { Collagen type III formation } \\ \text { PRO-C4 } & \text { Collagen type IV formation } \\ \text { C1M } & \text { MMP-mediated collagen type I degradation } \\ \text { C3M } & \text { MMP-mediated collagen type III degradation } \\ \text { C4M } & \text { MMP-mediated collagen type IV degradation } \\ \text { MMP } & \text { Matrix metalloproteinase } \\ \text { OC } & \text { Osteocalcin } \\ \text { CTX-I } & \text { C-terminal telopeptide of collagen type I } \\ \text { RA } & \text { Rheumatoid arthritis } \\ \text { CASPAR } & \text { Classification criteria for psoriatic arthritis } \\ \text { TJC } & \text { Tender joint count } \\ \text { VAS } & \text { Visual analogue scale } \\ \text { HAQ } & \text { Health assessment questionnaire } \\ \text { ASDAS } & \text { Ankylosing spondylitis disease activity score } \\ \text { BASDAI } & \text { Bath ankylosing spondylitis disease activity } \\ & \text { index } \\ \text { BASMI } & \text { Bath ankylosing spondylitis metrology index } \\ \text { LEI } & \text { Leeds enthesitis index } \\ \text { SPARCC } & \text { Spondyloarthritis research consortium of } \\ & \text { Canada enthesitis index } \\ \text { PASI } & \text { Psoriasis area and severity index } \\ \text { SD } & \text { Standard deviation } \\ & \end{array}$

\section{Background}

Psoriatic Arthritis (PsA) is a chronic, inflammatory arthropathy of the peripheral and axial skeleton. PsA, in general, remains poorly defined because of its heterogeneous clinical presentation [1]. Pathologically, it is an autoimmune disease characterized by inflammation of the joints, entheseal sites and skin [2]. A major cause of disability in PsA is the destruction of the extracellular matrix (ECM) of cartilage, bone, and soft tissues of the joint $[3,4]$. This is attributed to effects of pro-inflammatory cellular infiltrate and elaboration of inflammatory cytokines underlying the pathology of PsA. The inflammatory joint milieu induces increased expression of proteolytic enzymes, such as the matrix metalloproteinases (MMPs), That mediate enhanced turnover of the ECM $[5,6]$. These ECM fragments may enter circulation and may be utilised as serological biomarkers of ECM turnover.

Degradation and formation of ECM proteins are in a tight equilibrium ensuring tissue health and homeostasis. This equilibrium is perturbed by the inflammatory load in PsA patients leading to altered balance of the ECM [7]. During this process, excessive levels of collagen fragments (neo-epitopes) are released into the circulation and may act as important biomarkers in the study of tissue-related remodelling. These biomarkers can also provide insight into identification of key molecular pathways leading to enhanced connective tissue remodelling.

The ECM can be divided into the basement membrane and interstitial matrix. Collagen types I and III are the most abundant collagens in soft tissue and are located in the interstitial matrix. Collagen type I is therefore predominant in both bone matrix and tissue. Collagen type III is found extensively in connective tissues, such as skin, and vascular system, and is found to be a key player in wound healing together with collagen type I $[8,9]$. Collagen type IV is the main collagen component of the basement membrane, underlying epithelial or endothelial cells functioning as barrier between tissue compartments [10]. Besides soft tissues, the bone remodelling processes underlying PsA pathology can also be assessed objectively by the use of serological biomarkers. Here, the C-terminal telopeptide of collagen type I (CTX-I) measures the degradation of collagen type I by cathepsin $\mathrm{K}$, an enzyme secreted by osteoclasts during bone resorption [11]. Several studies have established CTX-I as a specific and sensitive biomarker of bone resorption [12]. A second marker of bone turnover is osteocalcin $(\mathrm{OC})$, which is one of the major non-collagenous proteins of bone matrix synthesized by active osteoblasts [13]. OC is a well-established markers of bone formation, and are found to correlate with histomorphometric bone formation indices $[13,14]$. Increased bone remodelling and elevated levels of both degradation and formation markers have been documented in PsA patients previously [15]. An example of this was presented in 2015, where biomarkers of collagen type I degradation (C1M) and collagen type III degradation (C3M) were increased in PsA patients compared to healthy individuals.

The outlook of PsA has significantly changed in the past decades due to availability of various treatment options including conventional and biological disease-modifying antirheumatic drugs (DMARDs) and the recently released targeted synthetic disease-modifying antirheumatic drugs [16]. However, while other types of arthritis have seen significant improvements in outcomes with newer treatments, approximately half of the PsA patients still experience an insufficient response [17, 18].

Marine n-3 polyunsaturated fatty acids (PUFAs), such as eicosapentaenoic acid (EPA; 20:5n-3) and docosahexaenoic acid (DHA; 22:6n-3), found in fish and fish oils, have been proposed as potential therapeutic or supplementary agents in a variety of acute and chronic inflammatory settings. At sufficiently high intakes, n-3 PUFAs can act as 
anti-inflammatory agents by decreasing the production of arachidonic acid-derived inflammatory eicosanoids like prostaglandins and leukotrienes, pro-inflammatory cytokines, reactive oxygen species and the expression of adhesion molecules $[19,20]$. Evidence of their clinical benefit is reasonably strong in some settings (eg, in RA [21, 22], cardiovascular disease [23], neurological diseases [24-26] and osteoarthritis [27, 28]) and weak in others (e.g., inflammatory bowel diseases and asthma). Recent randomized and controlled trial using n-3 PUFA has demonstrated a reduction in joint pain and non-steroidal anti-inflammatory drugs NSAIDs use in patients with PsA and RA [20, 29]. The clinical efficacy of n-3 PUFAs in arthritis can be attributed to their effect on inflammation and/or bone remodelling. Both mechanisms have been addressed individually in in vivo and in vitro setups [30-34]. However, the relative contribution of these mechanisms in various types of arthritis remains unexplored.

Biomarkers of ECM turnover can provide this valuable information regarding mechanism of action of n-3 PUFAs in arthritis. In this study, we aimed to explore the hypothesis that ECM turnover described by neo-epitope biomarkers can separate PsA patients from healthy individuals and patients treated with n-3 PUFA from the placebo group.

\section{Methods}

\section{Study design and population}

A randomized, double-blind, placebo-controlled trial was conducted and the subjects, study design, inclusion and exclusion criteria, randomization and sample size calculation has been described in details previously [29]. For 24 weeks, patients were assigned to a daily intake of either $3 \mathrm{~g}$ of marine n-3 PUFA (50\% EPA and 50\% DHA) or $3 \mathrm{~g}$ of olive oil (approximately $80 \%$ of oleic acid and $20 \%$ linoleic acid). Treatment with biological DMARDs or oral corticosteroids was exclusion criterion. Conventional DMARDs, NSAID and paracetamol intake were allowed.

All participants gave their written informed consent and the regional ethics committee of Northern Denmark approved the study (reference number N20120076). The study was conducted in accordance with the Declaration of Helsinki and registered at ClinicalTrials.gov (NCT01818804). Good Clinical Practice (GCP) inspectors monitored the study, and the GCP ethical and scientific quality requirements were fulfilled. The primary outcome of the study was disease activity measured by tender and swollen joint count [29]. This study is a sub-study investigating biomarkers of tissue remodelling as secondary outcomes. Blood samples were obtained from the study participants, at baseline and at the study end, in non-fasting state. Serum samples were collected and processed immediately after collecting according to standard operating procedures and stored at $-80{ }^{\circ} \mathrm{C}$ until analysis. For this sub-study, fifty-seven healthy individuals were included as controls, randomly selected and purchased from Lee Biosolutions (CA, US). Serum samples from the healthy individuals were collected in 2018 and processed immediately after collecting according to standard operating procedures and stored at $-80{ }^{\circ} \mathrm{C}$ until analysis.

\section{Biomarker analysis}

ECM remodelling was assessed by a panel of biomarkers including validated ELISAs of Matrix-metalloproteinasegenerated neo-epitope fragments of collagen type I, III and IV was chosen to assess collagen degradation (C1M, C3M, and $\mathrm{C} 4 \mathrm{M}$, respectively) and formation (PRO-C1, PRO-C3 and PRO-4, respectively) were run by manufactures instruction. Bone remodelling was assessed by osteocalcin (OC) and CTX-I. OC was measured using the Elecsys ${ }^{\circledR}$ osteocalcin kit (Roche Diagnostic Ltd., Switzerland), while CTX-I was measured by the Elecsys ${ }^{\circledR} \beta$-CrossLaps assay (Roche diagnostics Ltd., Switzerland). Reference levels for OC and CTX-I were obtained from the package insert of the
Table 1 Overview of measured biomarkers representing ECM turnover

\begin{tabular}{lll}
\hline Biomarker & Measures & Reference \\
\hline Collagen 2 turnover & & {$[43]$} \\
PRO-C1 & Formation of collagen type I & {$[44]$} \\
PRO-C3 & Formation of collagen type III & {$[45]$} \\
PRO-C4 & Formation of collagen type IV & {$[46]$} \\
C1M & MMP-2, -9, -13 mediated degradation of collagen type I & {$[47]$} \\
C3M & MMP-9 mediated degradation of collagen type III & {$[48]$} \\
C4M & MMP-2, -9, -12 mediated degradation of collagen type IV & \\
Bone turnover & & {$[41]$} \\
OC & Osteocalcin & {$[42]$} \\
CTX-I & C-terminal telopeptide of collagen type I \\
\hline
\end{tabular}

MMP Matrix-metalloproteinase 
individual assays $(n=6)$. The biomarkers are described in Table 1.

\section{Statistical analysis}

Sample size calculation has been described previously [29]. Analyses were performed in MedCalc (version 14.8.1) and GraphPad Prism (version 8). A $p$ value below 0.05 was considered statistically significant. Baseline characteristics of healthy individuals, placebo and n-3 PUFA-treated patients were presented as mean \pm standard deviation (SD) for continuous variables and number (frequency) for categorical variables. Differences between the groups were calculated using Pearson's Chi-square for categorical variables and ANOVA (parametric) or Kruskal-Wallis test (non-parametric) for continuous variables. An unpaired $t$ test was used to calculate statistical differences between PsA patients and healthy individuals, when data passed the Bartlett's variation test. If data did not pass, a non-parametric Wilcoxon-Mann-Whitney $t$ test was used. A paired $t$ test was used for evaluation of treatment at baseline and after 24 weeks. Spearman's correlations were used to analyse the associations between the biomarker and clinical feature at baseline and after 24 weeks.

\section{Results}

\section{Demographics}

A total of 142 patients with PsA, 71 patients in the $n-3$ PUFA group and 71 patients in the placebo group (Fig. 1) and 57 healthy individuals were included in this study. Patient demographics and clinical characterization for the intervention group were compared to baseline characteristics, disease activity scores, and biomarker levels (Table 2) without significant difference and the excluded patients did not differ from those who completed the trial.

\section{Associations between the biomarkers and clinical parameters}

Associations between clinical parameters and biomarkers are found in Table 3. A negative correlation was found between CTX-I and DAS-28-CRP $(r=-0.199, p=0.018)$, PROC3 and TJC ( $r=-0.267, p=0.01)$ and OC; CTX-I; PRO$\mathrm{C} 1$ and SJC $(r=-0.234, p=0.005 ; r=-247, p=0.003$; $r=-0.236, p=0.005$, respectively). A positive correlation was found for C3M and SPARCC $(r=0.171, p=0.042)$. No correlation was found for the other clinical measures and ASDAS-CRP, PASI, LEI, HAQ, BASDAI and VAS pain.

\section{Extracellular matrix turnover}

The biomarkers measuring ECM turnover in soft tissue, PRO-C1, measuring collagen type I formation, did not show a difference between the healthy controls and PsA patients ( $p=0.056$, Fig. $2 \mathrm{a}$ ), while $\mathrm{C} 1 \mathrm{M}$, measuring collagen type I degradation was $56 \%$ elevated in patients with PsA $(p<0.0001$, Fig. 2b). A $76 \%$ increase was found for PRO-C3, collagen type III formation in patients with PsA compared to healthy individuals $(p<0.0001$, Fig. $2 c)$, while no difference was found for the collagen type III degradation marker C3M ( $p=0.462$, Fig. $2 d)$. An increase in both formation and degradation of collagen type IV, reflected by PRO$\mathrm{C} 4$ and $\mathrm{C} 4 \mathrm{M}$, was found (both $p<0.0001$ and an increase of $792 \%$ and $70 \%$, respectively, Fig. 2e and Fig. 2f).

The ECM biomarkers measuring bone formation, OC, and bone degradation, CTX-I, were not statistically different in PsA patients compared to healthy individuals (Fig. 3). A trend towards a decreased level of OC in PsA patients was observed ( $p=0.06$, Fig. 2a

).

\section{Effect of $n-3$ PUFA supplementation on bone and tissue turnover biomarkers}

Neither of the bone turnover biomarkers, OC or CTX-I, showed changes in either patients treated with placebo or patients treated with n-3 PUFA for 24 weeks (Fig. 4a and Fig. 4b). PRO-C3 was the only tissue biomarker which was significantly elevated by $7 \%$ in patients receiving PUFA-3 $(p=0.002$, Fig. $4 d$ ), none of the other tissue biomarkers showed a significant difference with n-3 PUFA treatment from placebo.

\section{Discussion}

Tissue remodelling is a feature of PsA pathology. Treatment of PsA therefore aims not only to resolve inflammation but also to halt or slow down the ongoing tissue damage. In the present study, we measured ECM turnover biomarkers in healthy individuals, biologic naïve patients with PsA and biologic naïve patients with PsA treated with n-3 PUFA for 24 weeks. To our knowledge, this is the first study assessing tissue neo-epitope biomarkers in a randomised clinical study of patients with PsA. The evaluated tissue biomarkers are anchored in both the interstitial matrix and basement membrane and could therefore potentially be used to describe disease activity in PsA. 


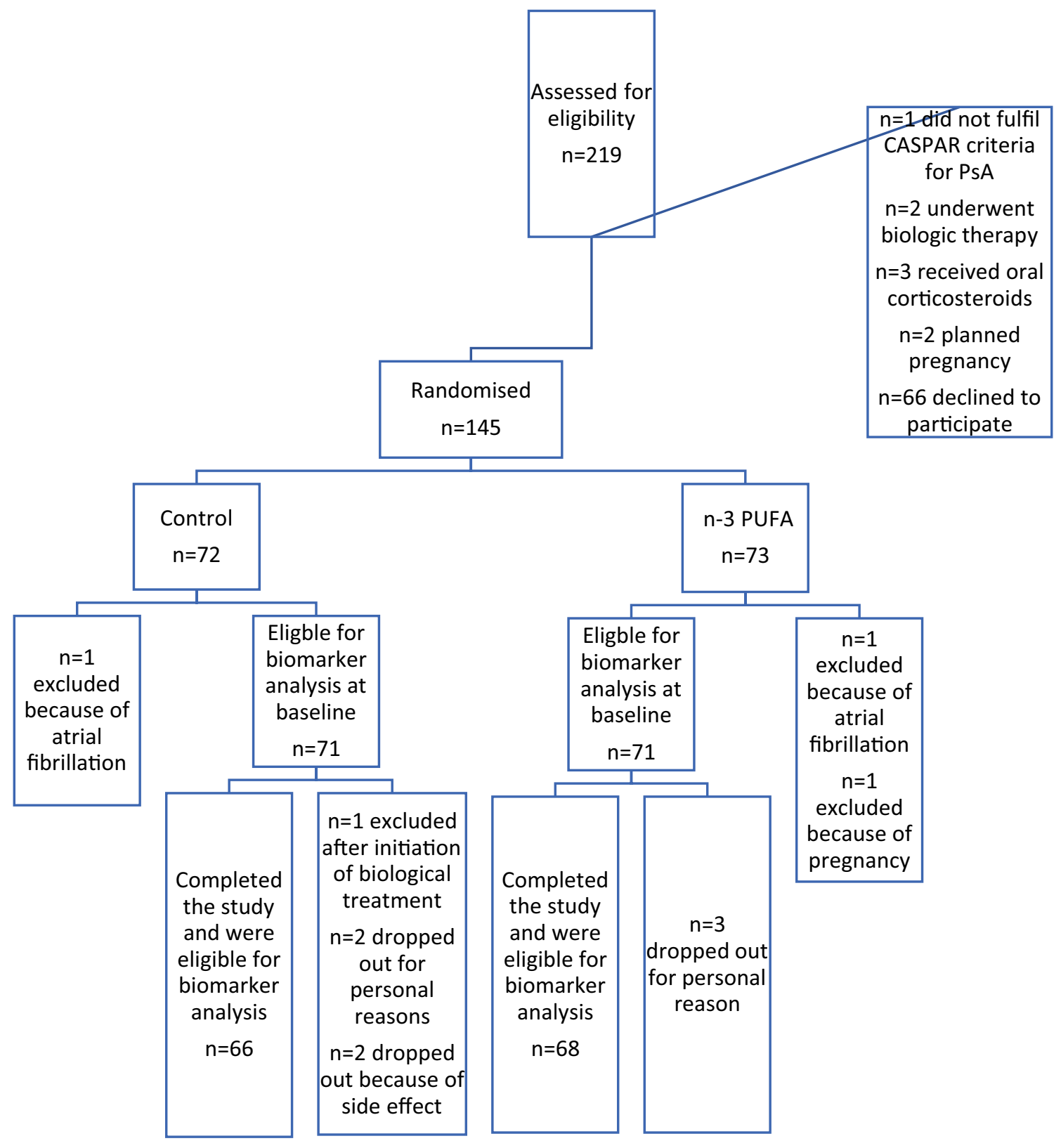

Fig. 1 Flowchart of the trial

N-3 PUFA, especially long-chain n-3 PUFA like eicosapentaenoic acid (EPA) and docosahexaenoic acid (DHA), has shown bone-protective effects in animal models by inhibiting bone resorption and promoting bone formation [35]. Several studies in humans have also been done to assess the effect of n-3 PUFA supplementation on bone health, most of which are done in healthy individuals, some in patients with RA and very few in patients with PsA. Some studies have reported modulation of bone biomarkers after $n-3$ PUFA intervention $[34,36,37]$ while others have reported no effect [38, 39].

Anti-inflammatory and pro-resolving effects of $n-3$ PUFA have been well-established during the past decades. 
Table 2 Demographics

\begin{tabular}{|c|c|c|c|c|}
\hline Variable & $\begin{array}{l}\text { Controls } \\
n=57\end{array}$ & $\begin{array}{l}\text { Placebo } \\
n=71\end{array}$ & $\begin{array}{l}\text { PUFA } \\
n=71\end{array}$ & $p$ value \\
\hline Mean age (SD) & $39.6(11.8)$ & $50.7(11.5)$ & $53.0(11.4)$ & $<0.001$ \\
\hline Gender, female (\%) & $22(37 \%)$ & $43(60.6)$ & $40(55.6)$ & 0.038 \\
\hline PsA duration & N/A & $13.4(8.9)$ & $13.4(10.0)$ & 0.983 \\
\hline BMI $\left(\mathrm{kg} / \mathrm{m}^{2}\right)$ & N/A & $28.0(5.0)$ & $28.6(5.8)$ & 0.529 \\
\hline \multicolumn{5}{|l|}{ Smoking, $n(\%)$} \\
\hline Non-smoker & N/A & $41(57.7)$ & $36(50.0)$ & 0.164 \\
\hline Former smoker & & $14(19.7)$ & $27(37.5)$ & \\
\hline Current smoker & & $16(22.5)$ & $9(12.5)$ & \\
\hline SJC & N/A & $0.8(2.0)$ & $0.6(1.9)$ & 0.420 \\
\hline TJC & N/A & $4.0(5.9)$ & $5.1(9.6)$ & 0.424 \\
\hline ASDAS & N/A & $2.3(1.1)$ & $2.0(0.9)$ & 0.038 \\
\hline BASDAI & N/A & $38.1(26.3)$ & $32.6(24.1)$ & 0.199 \\
\hline BASMI & N/A & $1.1(4.0)$ & $1.5(7.3)$ & 0.669 \\
\hline DAS-28 & N/A & $2.7(0.9)$ & $2.5(0.9)$ & 0.188 \\
\hline LEI & N/A & $1.3(1.6)$ & $1.3(1.7)$ & 0.802 \\
\hline PASI & N/A & $2.3(4.0)$ & $2.2(3.0)$ & 0.897 \\
\hline SPARCC & N/A & $2.7(3.3)$ & $2.5(3.3)$ & 0.703 \\
\hline CRP (mg/L) & N/A & $6.1(7.7)$ & $4.6(4.2)$ & 0.149 \\
\hline VAS pain & N/A & $37.0(24.3)$ & $29.80(24.0)$ & 0.085 \\
\hline NSAID use $n(\%)$ & N/A & $32(45.1)$ & $40(55.6)$ & 0.746 \\
\hline DMARD use $n(\%)$ & N/A & $50(70.4)$ & $57(79.2)$ & 0.136 \\
\hline $\begin{array}{l}\text { Documented coronary heart dis- } \\
\text { ease, } n(\%)\end{array}$ & N/A & $4(5.6)$ & $4(5.6)$ & 1.000 \\
\hline Hypertension, $n(\%)$ & N/A & $20(28.2)$ & $21(29.2)$ & 0.813 \\
\hline Hypercholesterolemia, $n(\%)$ & N/A & $11(15.5)$ & $18(25.0)$ & 0.147 \\
\hline Total cholesterol, $(\mathrm{mmol} / \mathrm{l})$ & N/A & $4.8(0.8)$ & $5.0(1.0)$ & 0.196 \\
\hline Systolic BP, (mmHg) & N/A & $134.3(19.2)$ & $137.8(18.0)$ & 0.275 \\
\hline Diastolic BP, (mmHg) & N/A & $82.0(12.3)$ & 82.7 (10.9) & 0.699 \\
\hline
\end{tabular}

$S D$ standard deviation, $B M I$ body mass index, $S J C$ swollen joint count, $T J C$ tender joint count, $A S D A S$ the ankylosing spondylitis disease activity score, BASDAI bath ankylosing spondylitis disease activity index, BASMI bath ankylosing spondylitis meterology index, $D A S-28$ disease activity score-28 joints, $L E I$ Leeds enthesitis index, PASI Psoriasis area and severity index, SPARCC spondyloarthritis research consortium of canada, CRP C-reactive protein, VAS visual analounge scale, NSAID non steroidal anti-inflammatory drug, $D M A R D$ disease modifying anti-rheumatic drugs, $N / A$ not available

The underlying mechanisms responsible for n-3 PUFA's biological effects are mediated by the production of proresolving mediators, which have been proposed to modulate and likely resolve inflammatory responses [40]. Therefore, various studies have been carried out to explore therapeutic potential of n-3 PUFA supplementation in inflammatory diseases including inflammatory arthritides [41]. A number of studies have been carried out in patients with RA and other inflammatory diseases that have reported an inverse correlation between n-3 PUFA use and CRP and erythrocyte sedimentation rate [42-44]. In addition to reduced inflammation, n-3 PUFA treatment has also showed a reduced joint pain and NSAID use in patients with RA, and a reduction in use of NSAIDs and paracetamol in patients with PsA [29]. Nevertheless, only a few small studies have examined the 
Table 3 Correlations between biomarkers and clinical scores

\begin{tabular}{|c|c|c|c|c|c|c|c|c|c|c|}
\hline Biomarker & ASDAS-CRP & DAS-28-CRP & TJC & PASI & SJC & LEI & SPARCC & HAQ & BASDAI & VAS pain \\
\hline $\mathrm{OC}$ & Ns & Ns & Ns & Ns & $\begin{array}{l}r=-0.234 \\
p=0.005\end{array}$ & Ns & Ns & Ns & Ns & Ns \\
\hline CTX-I & Ns & & Ns & Ns & $\begin{array}{l}r=-0.247 \\
p=0.003\end{array}$ & Ns & Ns & Ns & Ns & Ns \\
\hline PRO-C1 & Ns & Ns & Ns & Ns & $\begin{array}{l}r=-0.236 \\
p=0.005\end{array}$ & Ns & Ns & Ns & Ns & Ns \\
\hline PRO-C3 & Ns & Ns & $\begin{array}{l}r=-0.267 \\
p=0.01\end{array}$ & Ns & Ns & Ns & Ns & $\mathrm{Ns}$ & Ns & Ns \\
\hline PRO-C4 & Ns & Ns & Ns & Ns & Ns & Ns & Ns & Ns & Ns & Ns \\
\hline $\mathrm{C} 1 \mathrm{M}$ & Ns & Ns & Ns & Ns & Ns & Ns & Ns & Ns & Ns & Ns \\
\hline $\mathrm{C} 3 \mathrm{M}$ & Ns & Ns & Ns & Ns & Ns & Ns & $\begin{array}{l}r=0.171 \\
p=0.042\end{array}$ & Ns & Ns & Ns \\
\hline $\mathrm{C} 4 \mathrm{M}$ & Ns & Ns & Ns & Ns & Ns & Ns & Ns & Ns & Ns & Ns \\
\hline
\end{tabular}

$N s=$ non significant

effect of n-3 PUFA on clinical outcomes and inflammation in patients with PsA with diverging results [45-47].

In general, several studies have indicated a disturbance in lipids in PsA patients, by an increased serum concentration of triglycerides, cholesterol, LDH and HDL [48, 49]. Saturated fatty acids (myristic acid, palmitic acid, stearic acid, arachidic acid, behenic acid, lognoceric acid) are believed to have pro-inflammatory effects, while MUFA (palmutoleic acid, oleic acid, nervonic acid) and PUFA have shown antiinflammatory effects [50]. In addition, the compositions of fatty acids, are less important that the overall fatty acid composition [51]. Due to lack of research within the composition of fatty acids in PsA, only speculations on how tissue biomarkers will be modulated dependent on the fatty acid supplement.

In this study, we were unable to demonstrate any changes in biomarkers of bone and tissue turnover after intervention. Only a significant change was found with an increase in PRO-C3 from baseline to 24 weeks, however no relevant clinical finding. The primary outcomes of the clinical trial were not reached and indicated no difference in placebo vs. n-3 PUFA supplement which may describe the lack of changes in the biomarkers [29]. Supplementation with n-3 PUFA for 24 weeks might be too short a period to observe changes and modulation in these biomarkers. Furthermore, patients in this study had a low mean disease activity score of $2.6(\mathrm{SD}=0.9)$ at baseline and $75 \%$ of the patients received disease-modifying antirheumatic drugs. Thus, we investigated a patient group in remission and results may not apply to patients with a more severely disease activity or patients not receiving DMARDs.

\section{Limitations and strengths}

The present study had some limitations. First, olive oil was used as placebo and while there are reports on the use of olive oil for this purpose in studies investigating the effects of n-3 PUFA [23, 52], it may itself have anti-inflammatory effects owing to its numerous phenol constituents [53]. These effects of olive oil might explain the lack of a significant difference in inflammatory biomarkers between the groups. Second, patients with all disease activity scores were included in the study and they had a low disease activity at baseline (low mean swollen and tender joint count, enthesitis 

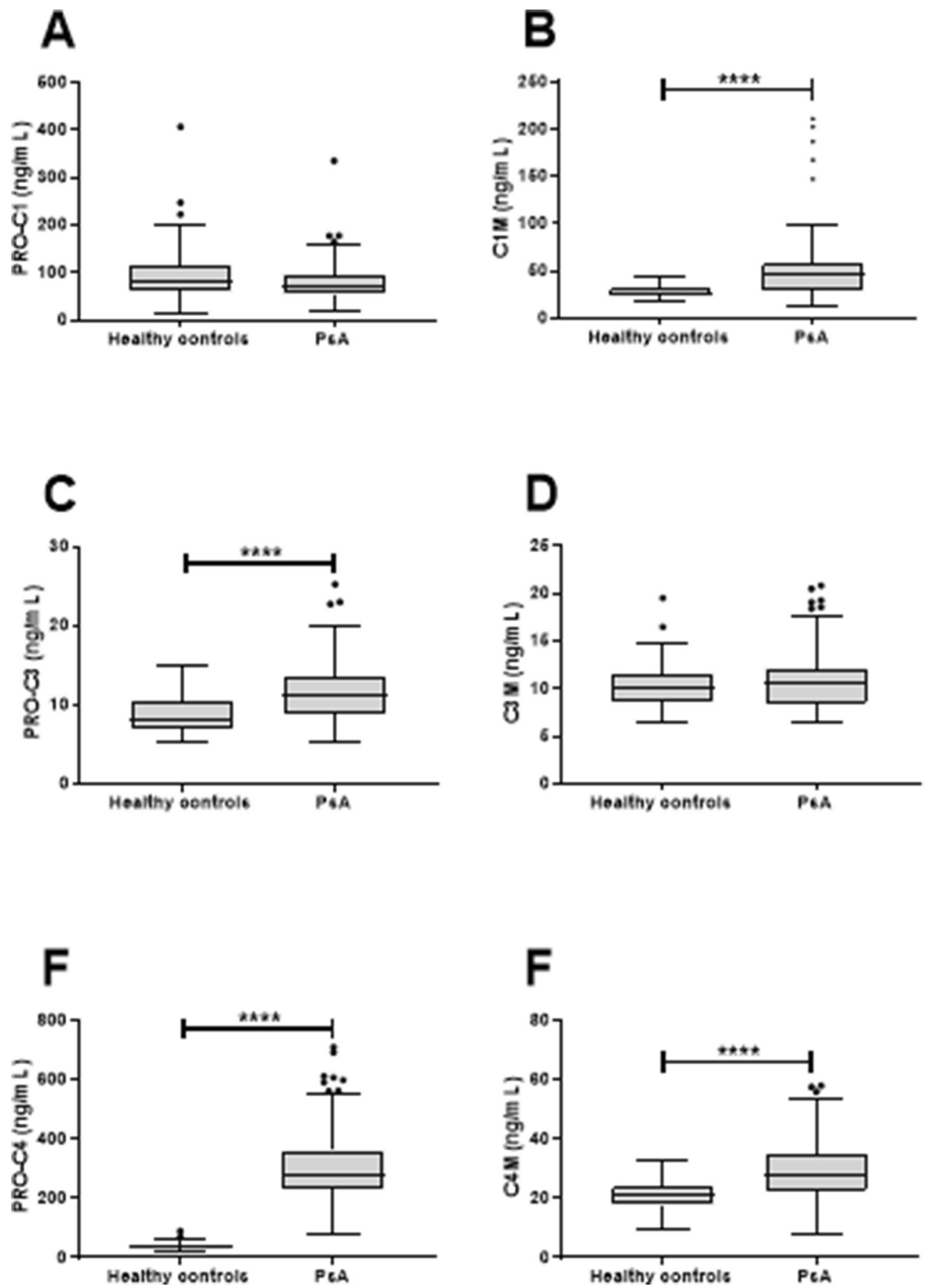

Fig. 2 Levels of collagen formation and degradation biomarkers in serum from healthy controls $(n=57)$ and patients with PsA $(n=142)$. a. Serum levels of formation of collagen type I (PRO-C1), b. Serum levels of degradation of collagen type I (C1M), c. Serum levels of formation of collagen type III (PRO-C3), d. Serum levels of degradation of collagen type III, e. Serum levels of formation of collagen

type VI (PRO-C4), b. Serum levels of degradation of collagen type IV (C4M). Statistical differences between the healthy controls and PsA patients were calculated using an unpaired $t$ test for PRO-C3, and LOG10 transformed PRO-C1, C1M, C3M, PRO-C4 and C4M. Significance threshold was set at $p<0.05$ and data is presented as Tukey boxplots. Significance levels: $* * * * p<0.0001$ 


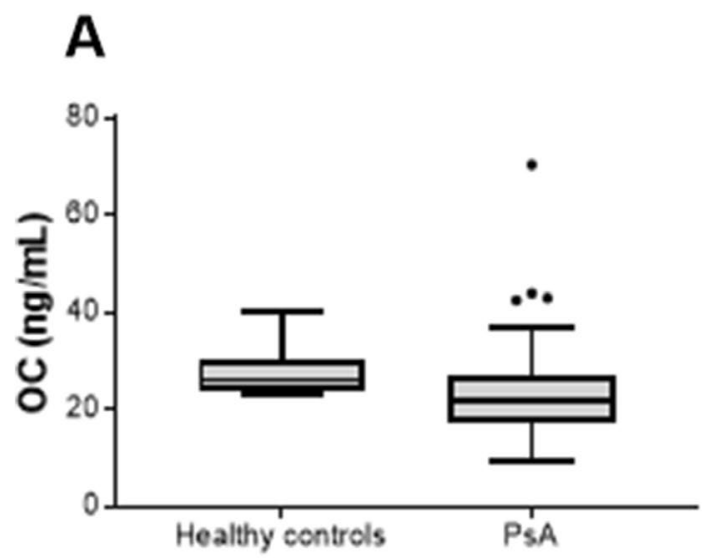

Fig. 3 Levels of bone formation and degradation biomarkers in serum from healthy controls $(n=6)$ and patients with PsA $(n=142)$. a. Serum levels of bone formation measured by osteocalcin (OC) and b. Serum levels of bone degradation measured by CTX-I. Statistical

score and PASI) owing to DMARD use in about $75 \%$ and NSAID use in $50 \%$ of the patients. Third, the effect of $n-3$ PUFA on clinical outcomes and thereby biomarkers is likely to be small in comparison to DMARDs, thus requiring a larger sample size. Lastly, blood samples were not collected in fasting state for this study, which could have influenced the results, especially CTX-I.

The main strength of the study is the double-blind, randomized, and prospective design comparing subjects which are biologic naïve. Furthermore, the compliance rate was good and only few patients were lost to follow-up.
B

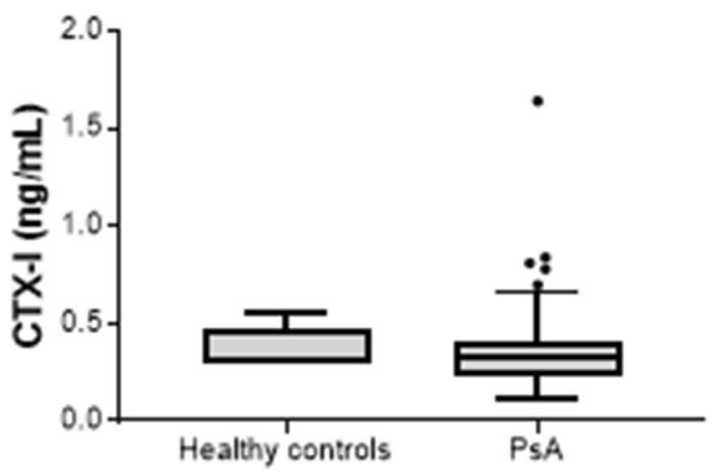

differences between the healthy controls and PsA patients were calculated using an unpaired $t$ test for OC, and LOG10 transformed CTX-I. Data is presented as Tukey boxplots

\section{Conclusion}

Patients with PsA showed an imbalanced ECM turnover compared to healthy individuals. No major differences were found for the biomarkers when the patients were treated with n-3 PUFA for 24 weeks. This indicates that tissue remodelling is occurring in the PsA patients compared to healthy individuals, but the n-3 PUFA treatment for 24 weeks does not have an effect on ECM turnover. However, further longterm studies are required to evaluate the potential effect of n-3 PUFA on PsA. 
Fig. 4 Biomarker levels in placebo $(n=57)$ and n-3 PUFA $(n=142)$ treated patients at baseline and 24 weeks. a Serum levels of the bone formation biomarker osteocalcin (OC), b Serum levels of the bone degradation biomarker CTX-I, c Serum levels of the collagen type I biomarker, PRO-C1, $\mathbf{d}$ Serum levels of the collagen type III formation biomarker, PRO-C3, e Serum levels of the collagen type IV formation biomarker, PRO-C4, f Serum levels of the collagen type I degradation biomarker, C1M, g Serum levels of the collagen type III degradation biomarker C3M, and h Serum levels of the collagen type IV degradation biomarker, C4M. Statistical differences between the baseline and 24 weeks of follow-up were calculated using a paired $t$ test for OC and PRO-C 3 , and LOG10 transformed CTX-I PRO-C1, C1M, C3M, PRO-C4 and $\mathrm{C} 4 \mathrm{M}$. Significance threshold was set at $p<0.05$ and data is presented as Tukey boxplots. Significance levels: ${ }^{* *} p<0.01$
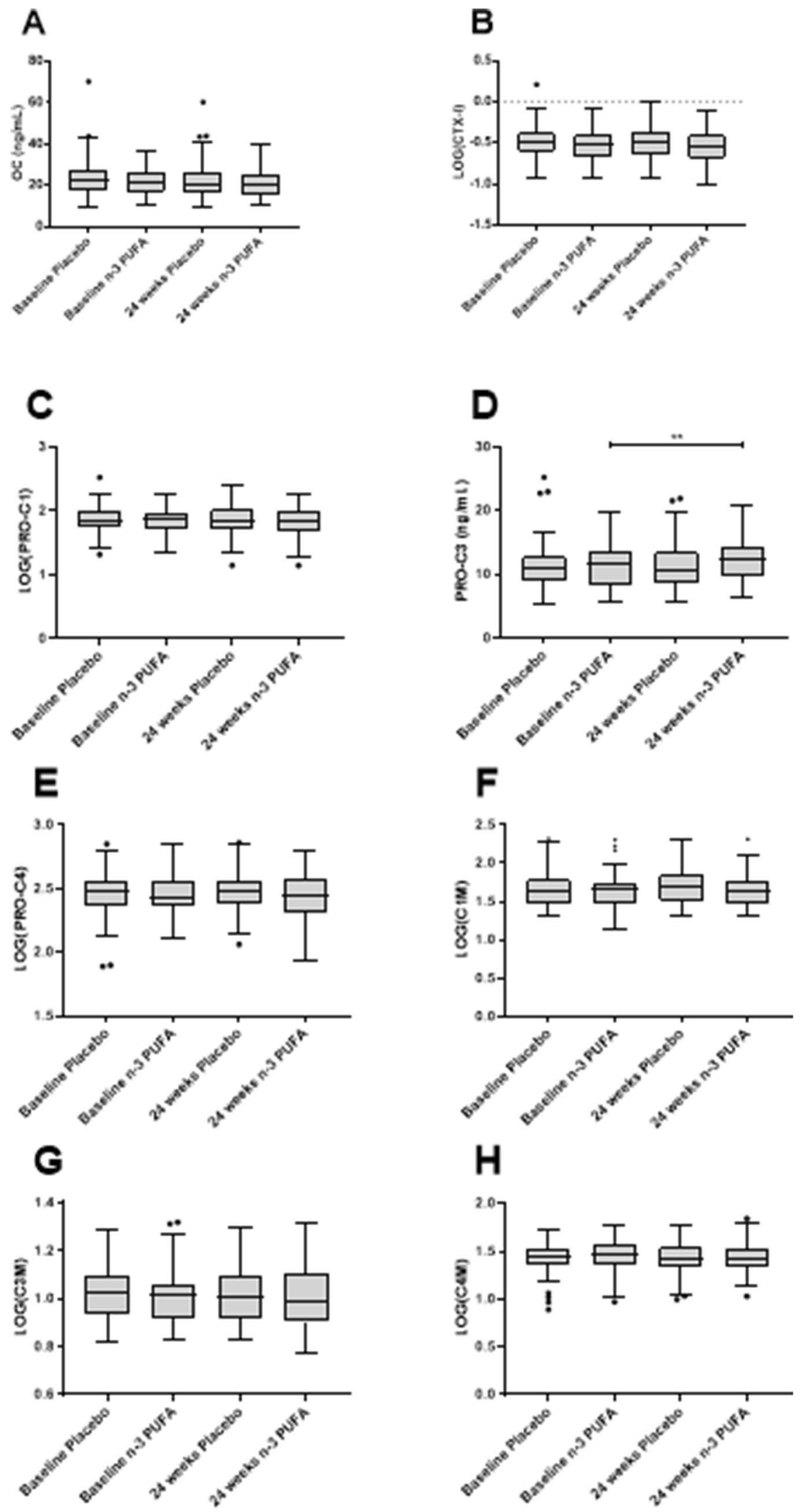
Acknowledgements We are grateful for the technical support of Zohreh Jamasbi Løvlien.

Author contributions SHN carried out biomarker analysis, statistical analysis together with SK and ACBJ and drafted the manuscript. SSA and ASS carried out the biomarker measurements and initiated the scientific collaboration between the groups. AS, EBS, JHC and SK performed the clinical trial and provided patient information. All authors were involved in the interpretation of the data. All authors edited the manuscript, with MK, ACBJ, JHC and SK providing metriculous revisions. All authors approved the final manuscript.

Funding This work was supported by the Danish Research Foundation "Den Danske Forskningsfond" and the Danish Innovation Foundation (Innovationsfonden), which funded the biomarker measurements and analysis; And the Danish Rheumatism Association and the Danish Psoriasis Foundation, which both funded the clinical trial.

Data availability The datasets used and/or analysed during the current study are available from the corresponding author on reasonable request.

\section{Declarations}

Conflict of interest SHN, ASS, ACBJ and MAK are full-time employees at Nordic Bioscience A/S. Nordic Bioscience is a privately-owned, small-medium size enterprise (SME) partly focused on the development of biomarkers. None of the authors received fees, bonuses or other benefits for the work described in the manuscript. MAK and ACBJ hold stocks in Nordic Bioscience A/S

Ethical approval and consent to participate All participants gave their written informed consent and the regional ethics committee of North Denmark approved the study (Reference number N20120076). The study was conducted in accordance with the Declaration of Helsinki and registered at ClinicalTrials.gov (NCT01818804).

Open Access This article is licensed under a Creative Commons Attribution 4.0 International License, which permits use, sharing, adaptation, distribution and reproduction in any medium or format, as long as you give appropriate credit to the original author(s) and the source, provide a link to the Creative Commons licence, and indicate if changes were made. The images or other third party material in this article are included in the article's Creative Commons licence, unless indicated otherwise in a credit line to the material. If material is not included in the article's Creative Commons licence and your intended use is not permitted by statutory regulation or exceeds the permitted use, you will need to obtain permission directly from the copyright holder. To view a copy of this licence, visit http://creativecommons.org/licenses/by/4.0/.

\section{References}

1. Mallbris L, Ritchlin CT, Ståhle M (2006) Metabolic disorders in patients with psoriasis and psoriatic arthritis. Curr Rheumatol Rep 8:355-363. https://doi.org/10.1007/s11926-006-0065-8

2. Veale DJ, Fearon U (2018) The pathogenesis of psoriatic arthritis. Lancet 391:2273-2284. https://doi.org/10.1016/S0140-6736(18) 30830-4

3. Schett G, Coates LC, Ash ZR et al (2011) Structural damage in rheumatoid arthritis, psoriatic arthritis, and ankylosing spondylitis: traditional views, novel insights gained from TNF blockade, and concepts for the future. Arthritis Res Ther. https://doi.org/10. 1186/1478-6354-13-S1-S4

4. Bartosińska J, Michalak-Stoma A, Juszkiewicz-Borowiec M et al (2015) The assessment of selected bone and cartilage biomarkers in psoriatic patients from Poland. Mediators Inflamm. https://doi. org/10.1155/2015/194535

5. Karsdal MA, Nielsen MJ, Sand JM et al (2013) Extracellular matrix remodeling: the common denominator in connective tissue diseases possibilities for evaluation and current understanding of the matrix as more than a passive architecture, but a key player in tissue failure. Assay Drug Dev Technol 11:70-92. https://doi. org/10.1089/adt.2012.474

6. Adair-Kirk TL, Senior RM (2008) Fragments of extracellular matrix as mediators of inflammation. Int $\mathbf{J}$ Biochem Cell Biol 40:1101-1110. https://doi.org/10.1016/j.biocel.2007.12.005

7. Moz S, Aita A, Basso D et al (2017) Spondyloarthritis: matrix metalloproteinasesas biomarkers of pathogenesis and response to tumor necrosis factor (TNF) inhibitors. Int J Mol Sci 18:830. https://doi.org/10.3390/ijms18040830

8. Clore JN, Cohen IK, Diegelmann RF (1979) Quantitation of collagen types I and III during wound healing in rat skin. Proc Soc Exp Biol Med 161:337-340. https://doi.org/10.3181/00379 727-161-40548

9. Volk SW, Wang Y, Mauldin EA et al (2011) Diminished type III collagen promotes myofibroblast differentiation and increases scar deposition in cutaneous wound healing. Cells Tissues Organs 194:25-37. https://doi.org/10.1159/000322399

10. Poschl E, Schotzer-Schrehardt U, Brachvogel B et al (2004) Collagen IV is essential for basement membrane stability but dispensable for initiation of its assembly during early development. Development 131:1619-1628. https://doi.org/10.1242/dev.01037

11. Christgau S, Bitsch-Jensen O, Hanover Bjarnason N et al (2000) Serum CrossLaps for monitoring the response in individuals undergoing antiresorptive therapy. Bone 26:505-511. https://doi. org/10.1016/S8756-3282(00)00248-9

12. Baim S, Miller PD (2009) Assessing the clinical utility of serum CTX in postmenopausal osteoporosis and its use in predicting risk of osteonecrosis of the jaw. J Bone Miner Res 24:561-574. https:// doi.org/10.1359/jbmr.090203

13. Szulc P (2018) Bone turnover: Biology and assessment tools. Best Pract Res Clin Endocrinol Metab 32:725-738. https://doi.org/10. 1016/j.beem.2018.05.003

14. Chavassieux P, Portero-Muzy N, Roux JP et al (2015) Are biochemical markers of bone turnover representative of bone histomorphometry in 370 postmenopausal women? J Clin Endocrinol Metab 100:4662-4668. https://doi.org/10.1210/jc.2015-2957

15. Jadon DR, Nightingale AL, McHugh NJ et al (2015) Serum soluble bone turnover biomarkers in psoriatic arthritis and psoriatic spondyloarthropathy. J Rheumatol 42:21-30. https://doi.org/10. 3899/jrheum.140223

16. D'Angelo S, Tramontano G, Gilio M et al (2017) Review of the treatment of psoriatic arthritis with biological agents: choice of drug for initial therapy and switch therapy for non-responders. Open Access Rheumatol Res Rev 9:21-28. https://doi.org/10. 2147/OARRR.S56073

17. Glintborg B, Ãstergaard M, Dreyer L et al (2011) Treatment response, drug survival, and predictors thereof in 764 patients with psoriatic arthritis treated with anti-tumor necrosis factor $\alpha$ therapy: results from the nationwide Danish DANBIO registry. Arthritis Rheum 63:382-390. https://doi.org/10.1002/art.30117

18. Felquer MLA, Coates LC, Soriano ER et al (2014) Drug therapies for peripheral joint disease in psoriatic arthritis: a systematic review. J Rheumatol 41:2277-2285. https://doi.org/10.3899/ jrheum. 140876 
19. Calder PC (2006) n-3 Polyunsaturated fatty acids, inflammation, and inflammatory diseases. Am J Clin Nutr 83:1505S-1519S. https://doi.org/10.1093/ajcn/83.6.1505S

20. Calder PC (2017) Omega-3 fatty acids and inflammatory processes: from molecules to man. Biochem Soc Trans 45:11051115. https://doi.org/10.1111/j.1365-2125.2012.04374.x

21. Veselinovic M, Vasiljevic D, Vucic V et al (2017) Clinical benefits of n-3 PUFA and $\gamma$-linolenic acid in patients with rheumatoid arthritis. Nutrients. https://doi.org/10.3390/nu9040325

22. Gioxari A, Kaliora AC, Marantidou F, Panagiotakos DP (2018) Intake of $\omega-3$ polyunsaturated fatty acids in patients with rheumatoid arthritis: a systematic review and meta-analysis. Nutrition 45:114-124.e4. https://doi.org/10.1016/j.nut.2017.06.023

23. De Caterina R (2011) N-3 fatty acids in cardiovascular disease. $\mathrm{N}$ Engl J Med 364:2439-2450. https://doi.org/10.1056/NEJMra1008 153

24. Michael-Titus AT (2007) Omega-3 fatty acids and neurological injury. Prostaglandins Leukot Essent Fat Acids 77:295-300. https://doi.org/10.1016/j.plefa.2007.10.021

25. Decker MJ, Jones K, Keating GL et al (2016) Maternal dietary supplementation with omega-3 polyunsaturated fatty acids confers neuroprotection to the newborn against hypoxia-induced dopamine dysfunction. Sleep Sci 9:94-99. https://doi.org/10.1016/j. slsci.2016.05.007

26. Devassy JG, Leng S, Gabbs M et al (2016) Omega-3 polyunsaturated fatty acids and oxylipins in neuroinflammation and management of Alzheimer's disease. Adv Nutr 7:905-916. https://doi.org/ 10.3945/an.116.012187.of

27. Wann AKT, Mistry J, Blain EJ et al (2010) Eicosapentaenoic acid and docosahexaenoic acid reduce interleukin-1 $\beta$-mediated cartilage degradation. Arthritis Res Ther. https://doi.org/10.1186/ $\operatorname{ar} 3183$

28. Knott L, Avery NC, Hollander AP, Tarlton JF (2011) Regulation of osteoarthritis by omega-3 (n-3) polyunsaturated fatty acids in a naturally occurring model of disease. Osteoarthr Cartil 19:1150 1157. https://doi.org/10.1016/j.joca.2011.06.005

29. Kristensen S, Schmidt EB, Schlemmer A et al (2018) Beneficial effect of n-3 polyunsaturated fatty acids on inflammation and analgesic use in psoriatic arthritis: a randomized, double blind, placebo-controlled trial. Scand J Rheumatol 47:27-36. https://doi. org/10.1080/03009742.2017.1287304

30. Watkins BA, Li Y, Allen KG et al (2000) Dietary ratio of (n-6)/ (n-3) polyunsaturated fatty acids alters the fatty acid composition of bone compartments and biomarkers of bone formation in rats. J Nutr 130:2274-2284. https://doi.org/10.1016/j.jnutbio.2005.05. 012

31. Watkins BA, Li Y, Lippman HE, Feng S (2003) Modulatory effect of omega-3 polyunsaturated fatty acids on osteoblast function and bone metabolism. Prostaglandins Leukot Essent Fat Acids 68:387-398. https://doi.org/10.1016/S0952-3278(03)00063-2

32. Yuan J, Akiyama M, Nakahama KI et al (2010) The effects of polyunsaturated fatty acids and their metabolites on osteoclastogenesis in vitro. Prostaglandins Other Lipid Mediat 92:85-90. https://doi.org/10.1016/j.prostaglandins.2010.04.001

33. Wauquier F, Léotoing $L$, Philippe $C$ et al (2015) Pros and cons of fatty acids in bone biology. Prog Lipid Res 58:121-145. https:// doi.org/10.1016/j.plipres.2015.03.001

34. Mangano KM, Sahni S, Kerstetter JE et al (2013) Polyunsaturated fatty acids and their relation with bone and muscle health in adults. Curr Osteoporos Rep 11:203-212. https://doi.org/10.1007/ s11914-013-0149-0

35. Lau BYY, Cohen DJA, Ward WE, Ma DWL (2013) Investigating the role of polyunsaturated fatty acids in bone development using animal models. Molecules 18:14203-14227. https://doi.org/10. 3390/molecules 181114203
36. Sharif PS, Asalforoush M, Ameri F et al (2010) The effect of n-3 fatty acids on bone biomarkers in Iranian postmenopausal osteoporotic women: a randomized clinical trial. Age (Omaha) 32:179-186. https://doi.org/10.1007/s11357-009-9122-3

37. Griel AE, Kris-Etherton PM, Hilpert KF et al (2007) An increase in dietary $\mathrm{n}-3$ fatty acids decreases a marker of bone resorption in humans. Nutr J 6:4-11. https://doi.org/10.1186/1475-2891-6-2

38. Rajaram S, Yip EL, Reghunathan R et al (2017) Effect of altering dietary n-6: n-3 polyunsaturated fatty acid ratio with plant and marine-based supplement on biomarkers of bone turnover in healthy adults. Nutrients. https://doi.org/10.3390/nu9101162

39. Damsgaard CT, Mølgaard C, Matthiessen J et al (2012) The effects of n-3 long-chain polyunsaturated fatty acids on bone formation and growth factors in adolescent boys. Pediatr Res 71:713-719. https://doi.org/10.1038/pr.2012.28

40. Serhan CN, Hong S, Gronert K et al (2002) Resolvins: a family of bioactive products of omega- 3 fatty acid transformation circuits initiated by aspirin treatment that counter proinflammation signals. J Exp Med 196:1025-1037. https://doi.org/10.1084/jem. 20020760

41. Molfino A, Amabile MI, Monti M, Muscaritoli M (2017) Omega-3 polyunsaturated fatty acids in critical illness: anti-inflammatory, proresolving, or both? Oxid Med Cell Longev 2017:1-6. https:// doi.org/10.1155/2017/5987082

42. Sundrarjun T, Komindr S, Archararit N et al (2004) Effects of $n-3$ fatty acids on serum interleukin- 6 , tumour necrosis factor- $\alpha$ and soluble tumour necrosis factor receptor $\mathrm{p} 55$ in active rheumatoid arthritis. J Int Med Res 32:443-454. https://doi.org/10.1177/ 147323000403200501

43. Sköldstam L, Börjesson O, Kjällman A et al (1992) Effect of six months of fish oil supplementation in stable rheumatoid arthritis. a double-blind, controlled study. Scand J Rheumatol 21:178-185. https://doi.org/10.3109/03009749209099218

44. Li K, Huang T, Zheng J et al (2014) Effect of marine-derived n-3 polyunsaturated fatty acids on C-reactive protein, interleukin 6 and tumor necrosis factor $\alpha$ : a meta-analysis. PLoS One. https:// doi.org/10.1371/journal.pone.0088103

45. Veale DJ, Torley HI, Richards IM et al (1994) A double-blind placebo controlled trial of efamol marine on skin and joint symptoms of psoriatic arthritis. Rheumatology 33:954-958. https://doi.org/ 10.1093/rheumatology/33.10.954

46. Madland TM, Björkkjaer T, Brunborg LA et al (2006) Subjective improvement in patients with psoriatic arthritis after short-term oral treatment with seal oil. A pilot study with double blind comparison to soy oil. J Rheumatol 33:307-310

47. Lassus A, Dahlgren AL, Halpern MJ et al (1990) Effects of dietary supplementation with polyunsaturated ethyl ester lipids (Angiosan) in patients with psoriasis and psoriatic arthritis. J Int Med Res 18:68-73. https://doi.org/10.1177/030006059001800109

48. Akhyani M, Ehsani AH, Robati RM, Robati AM (2007) The lipid profile in psoriasis: a controlled study. J Eur Acad Dermatol Venereol 21:1330-1332. https://doi.org/10.1111/j.1468-3083. 2007.02260.x

49. Frommer KW, Schäffler A, Rehart S et al (2015) Free fatty acids: potential proinflammatory mediators in rheumatic diseases. Ann Rheum Dis 74:303-310. https://doi.org/10.1136/annrh eumdis-2013-203755

50. Brouwers H, Von Hegedus J, Toes R et al (2015) Lipid mediators of inflammation in rheumatoid arthritis and osteoarthritis. Best Pract Res Clin Rheumatol 29:741-755

51. Mysliwiec H, Harasim-Symbor E, Baran A et al (2019) Abnormal serum fatty acid profile in psoriatic arthritis. Arch Med Sci 15:1407-1414. https://doi.org/10.5114/aoms.2019.89451

52. Goldberg RJ, Katz J (2007) A meta-analysis of the analgesic effects of omega-3 polyunsaturated fatty acid supplementation 
for inflammatory joint pain. Pain 129:210-223. https://doi.org/ 10.1016/j.pain.2007.01.020

53. Kremer JM, Lawrence DA, Jubiz W et al (1990) Dietary fish oil and olive oil supplementation in patients with rheumatoid arthritis. Clin Immunologic Eff Arthritis Rheum 33:810-820. https:// doi.org/10.1002/art.1780330607
Publisher's Note Springer Nature remains neutral with regard to jurisdictional claims in published maps and institutional affiliations. 